\title{
Erratum to: White Matter Microstructure and Subcortical Gray Matter Structure Volumes in Aspartylglucosaminuria; a 5-Year Follow-up Brain MRI Study of an Adolescent with Aspartylglucosaminuria and His Healthy Twin Brother
}

\author{
Anna Tokola • Nina Brandstack • Antti Hakkarainen • \\ Eero Salli • Laura Åberg • Taina Autti
}

Received: 6 September 2016 /Revised: 6 December 2016 / Accepted: 9 December 2016

(C) SSIEM and Springer-Verlag Berlin Heidelberg 2017

Erratum to: JIMD Reports

DOI: 10.1007/8904_2016_36

Publisher regrets that Acknowledgement and Funding information were not included in the published chapter.
The details are included in the updated version of the chapter.

The updated online version for this chapter can be found under DOI 10.1007/8904_2016_36

A. Tokola $(\bowtie) \cdot$ N. Brandstack $\cdot$ A. Hakkarainen $\cdot$ E. Salli $\cdot$ L. Åberg $\cdot$

T. Autti

HUS Medical Imaging Center, Helsinki, Finland

e-mail: anna.tokola@hus.fi 